\title{
Exploring on Chinese Foreign Trade Issues Based on E-Business
}

\author{
Shuqing Li \\ School of Business, North China Electricity Power University \\ Beijing 100089, China \\ E-mail: lshqing@sina.com
}

\begin{abstract}
Vigorous development of e-business in the world has produced profound influences upon foreign trade. While China's e-business has started late, its application in foreign trade has certain distance from that in developed countries. If China intends to be a strong country in the aspect of trade in the $21^{\text {st }}$ century, e-business must be greatly developed in the field of foreign trade. In this paper, the author anatomizes the application status quo of e-business in Chinese foreign trade and some existing problems through analyzing the effects of e-business on the international trade, that is, safety and conceptual issues for e-business, construction issue for information infrastructure, and legal system establishment issue. Finally, the author puts forward solutions and suggestions for promoting the application of e-business in Chinese foreign trade, such as changing concept and realizing importance of e-business, strengthening of network safety management, establishing and perfecting Chinese legal regulations for e-business, and continual strengthening of information infrastructure construction, etc..
\end{abstract}

Keywords: E-business, Foreign trade, International trade

In the 1940s-50s, the combination of computer technology and optical fiber based on micro-electronics technology opened the history of information and technology revolution. In 1970s, with the appearance of Electronic Data Interchange, people began to try to conduct automatic interchange of commercial data among different computers, which was an early form of e-business. After 1990s when e-business underwent a hard time, it still has obtained fast development in general.

MEANINGS OF E-BUSINESS AND ITS EFFECTS ON INTERNATIONAL TRADE

\section{Meaning of e-business}

In 1997, in "Economic and Social Effects of E-business", the Organization for Economic Co-operation and Development of United Nations (OECD) defined e-business as commodity trade that happens on the Internet between enterprises and enterprises, and between enterprises and consumers, including forms of text, audio and video images. In November of the same year, the International Chamber of Commerce pointed out in the e-business memo of Paris Conference, that e-business is a computerization for realizing the entire trade activities.

Effects of e-business on international trade

E-business is an approach to handing information, which can be applied into many fields, including international trade field. Especially, the development of Internet created premises and laid foundations for developing e-business for enterprises of different scales and made trade and information exchange among enterprises easier and cheaper.

Since the appearance and prevalence of e-business in the world, its effects on international trade have been embodied in all aspects, and extended towards deep levels from simple to complicated aspects. It has brought profound influences upon such aspects as international trade theory, international trade manner, international trade operating mechanism, marketing, macro-management, and trade policy, etc..

Firstly, e-business struck the traditional international trade theories. The traditional international free trade theories include the comparative advantage theory and the theory of endowment, which were both stricken by e-business. According to the comparative advantage theory, the traditional comparative advantages include differences among natural resources, capital, labor force and human resources, etc.. However, in the era of e-business, information flow runs through the whole proceeding of e-business. Information is a key inscape of e-business, and it has become an important production element and resource, so information comparative advantage is gradually turning into one of determinants of international trade; while the theory of endowment mainly analyzes the origin of supply trade from the aspect of supply, namely, different abundant degrees of elements in different countries lead to different element price. One country may 
make use of relatively low price elements in the production and international trade, which might bring comparative benefits to them. However, e-business lays more emphasis on satisfaction of customer demands provided by an enterprise, since demand plays a more and more indispensable part in the production and flow of products in the international trade.

Secondly, e-business has changed the traditional international trade manner. The international trade manner of e-business and that of tradition are different, mainly embodied in the followings: the first difference is the application of e-business and new mode of the international trade operating. E-business is a new international trade operating mode with information network as a carrier. In international e-business, all parties achieved international trade dealing by an electronic means, not by direct interview or face-to-face exchange. The second difference is the application of e-business and new types of the international trade mode. New types of international trade manner produced under the influence of e-business can be classified into complete international e-business and incomplete international e-business. The former is capable of fully excavating potential of the global e-business market; while the latter needs to rely on some external factors, because some material and non-digital commodities can not be delivered through Internet. Therefore, its dealing needs to rely on other activities and methods in addition to e-business. The third difference is the application of e-business and flow reformation of the international trade. Development and application of e-business will also further promote the flow reformation of the international trade, realize the reformation of the traditional trade flow and dealing which is based on transferring of paper trade bills (documents) as the principal part, and, therefore, form the new flow method of international trade.

Thirdly, e-business has changed the traditional marketing. In the era of e-business, a new marketing -virtual market emerges as the times require. According to statistics, at present, Internet has already covered almost 200 countries and regions in the world, and terminal users increase by degrees of $30 \%$ each year. The number of online computers has attained 70 million in China by now, that of Internet users have exceeded 172 million, and that of websites have already exceeded 1.31 million. E-business based upon Internet has become the global unified virtual dealing market. The virtual market opened another running space for commercial business. Although it has some common market essence with the traditional market, yet the difference between these two lies in: the virtual market breaks through the premise of the traditional market whose existence is based on the definite regional existence, and connects the world into a unified large "market" linked by information network. In this market, such information as commodity and service can flow in a sufficient and correct way in the whole world, indicating the features of publicity, integrity and real time, reducing information asymmetry of the importing and exporting parties, avoiding or lessening the distortion caused by the incompletion of market information, and therefore, ensuring the full functioning of the law of value.

Fourthly, e-business affects adopting direction of the international trade policy, since e-business has called for brand-new requirements for the international trade policy. Development of e-business has led to a series of policy propositions of the international trade: issues of demarcating the basic property of e-business, security, duty, and developing countries. E-business calls for human to fully take into account the ascription of its regulation inhibition and its behavior handling procedures in the future establishment of trade policy. E-business also enables economic safety of a country to be up against challenges. There is no last word whether promise made by members of WTO that tax would not be levied contemporarily on e-business will get continual recognition from each country with the further development of e-business. In the future establishment of e-business policy, whether the international society should establish feasible technological assistance system to help the developing countries make use of e-business and change from passive to active? All the previous issues put forward new challenges for the policy establishment of the global trade.

\section{APPLICATION STATUS QUO OF E-BUSINESS IN CHINESE FOREIGN TRADE}

Since earlier 1990s, the concept of e-business began to spread in China. In March 1998, the first Internet online deal was made, and since then, China's e-business has displayed a tendency of fast development from conceptual discussion to practical development.

\section{Law and humanity-oriented environment increasingly improved}

Relative regulations and laws of e-business have developed towards maturity, and fast development of e-business education and training has brought into shape an all-around and multi-level professional education and training system of e-business.

\section{Achievement of construction of network infrastructure}

After long-term construction of Chinese communications network, a network structure is formed with a combination of electronic network, data network, mobile network, image network, and multimedia network, technically realizing upgrading from man-computer network to automatic network, from simulating network to digital network, and from simplification network to diversification network. The period from 1990 to 2000 was a peak time of Chinese e-business investment, from 2001 to 2003 a foam period, and after 2003, Internet went through the lowest point period. Thereafter, venture investment focused on Internet and e-business again. 


\section{Improvement of payment environment}

Payment gets improved, and a nationwide bank card information exchange network is primarily established across banks and regions. Approximately 60 security certification institutions for e-business have been built around the country, and operating quality of Chinese interbank payment system gets effective enhancement.

\section{Rapid development of foreign trade}

E-business for the foreign trade evolves rapidly, so the trade volume continues to mount up. Such industries as electric power, textile and traffic all have their own industrial network, on which they release product information, conduct online negotiation and contract signing, and unfold network sale. According to CCID consulting statistics, trade volume in 2004 totaled RMB 480 billion, $73.7 \%$ more than that in 2003 .

\section{EXISTING PROBLEMS OF APPLICATION OF E-BUSINESS IN CHINESE FOREIGN TRADE}

Since 1990s with the application of EDI, e-business has evolved fast in China and has got delightful achievement, but there still exists some issues in the development of Chinese e-business.

\section{Safety issue of e-business}

Due to the fact that e-business is based upon Internet, the electronic currency is invisible, a great deal of economic information is transmitted on the Internet, and the capital is transferred on the Internet, the authoritative authentication of online trade requires no risk at all. However, as a matter of fact, safety of e-business is still worrisome internationally or domestically. Hidden safety trouble and risks are still prominent in terms of data transmission, handling and exchange between terminals. Particularly, with rapid development and prevalence of Internet, safety issues it faces more probably become a hotspot for human. In recent years, incidents about illegal invasion into computer network at home and abroad have emerged in endlessly, resulting in great economic damages to all countries. How to guarantee the safety of e-business activities will remain the core research area for e-business.

\section{Conceptual issues for e-business}

A large majority of Chinese enterprises have not had profound understanding in e-business. They still position competition focus on the real market, not fully convinced of necessity and urgency of occupying the network information virtual market in an economic era. According to the survey, at present only $10 \%$ of 15,000 state-owned large and medium-sized enterprises have basically implemented informationization, and cultural degree of medium and small-sized enterprises are even lower. Therefore, developing foreign trade by means of e-business has not aroused general attention from the huge Chinese enterprises. Even those enterprises which have already used e-business also have not really understood e-business of at all.

\section{Construction issue for information infrastructure}

Through several years' construction, our information infrastructure has acquired great progress, but still lags a lot behind the developed countries. Informationization and electronification degree of most Chinese enterprises are extremely low, and many enterprises even have not had any computers. Even though some enterprises have computers, they are mostly used to type and compute, while management of some important resources have not ever implemented electronification, such as production, supply, marketing, human resource, financing, and materials, etc.. Financial institutions still haven't realized electroni-fication, a nationwide financial network hasn't come into being, and in addition, commercial electronifica-tion lags behind financial electronification, some institutions even having not started. Furthermore, because of the fact that, network layout of all industries is not reasonable in China, separated and each in its own way, together with slow online speed, the enthusiasm for purchasing online is also affected.

\section{Legal system establishment issue}

In comparison with such western countries as US and EU, our legislation for e-business stills drops behind. Our government has already gradually realized the importance and urgency for this legislation, made modifications successively on relative laws, added articles for e-business development, and has continually released a series of Internet regulations. However, in one word, our current laws and regulations still display an overall blankness for e-business trade activities. Lagging in terms of legislation will cause domestic enterprises to be passive in the global e-business competition. Furthermore, disputes in the foreign trade are unavoidable, among which e-business dispute has its particularity. Due to the regional disparity, two trade parties respectively have their own legal system, and if no mature and unified legal system is established, disputes are not going to be perfectly resolved. Therefore, legislation for e-business is rather urgent.

\section{SOLUTIONS AND SUGGESTIONS FOR PROMOTING APPLICATION OF E-BUSINESS IN CHINESE FOREIGN TRADE}

\section{Changing concept towards e-business}

As what has been mentioned above, e-business has brought huge and profound effects upon the whole modern economic life, and has accelerated development of the international trade to a great extent. Therefore, we should change concept, 
and enhance understanding in e-business. That is to say, the entire society should put more efforts on propaganda, enhance the recognition of government and foreign trade enterprises on e-business, enable the huge foreign trade enterprises to understand, familiarize them with e-business, and adopt e-business. Especially for Chinese medium and small-sized enterprises, e-business provides an extremely convenient channel for them to enter the international market. So we should grasp opportunities to develop e-business. Only by this means, can we better participate in operating of the global economy, and share benefits of the international labor division.

\section{Enhancing network safety management}

Development of e-business calls for the resolution of safety and reliability issues. Network safety is connected to vital interests of every one. In e-business, unsafe network may bring direct economic damage, which will cause extremely disadvantageous impacts on the promotion of e-business, and make the public hesitate to move forward towards e-business. The government ought to exert all it can to establish a multi-level and exoteric network system that can guarantee information safety and integrality, reinforce establishment of a basic network, and build a safe, rigorous and reliable individual credit card and electronic currency payment system in the global sphere. The government should also set up and make sound safety authentication system, work out safety authentication management means for e-business, further control management of secret-key, certificates, and authentication institutions, and establish rationally distributed safety authentication system so as to provide reliable safety authentication service for the society. Finally, the government should continue to perfect and promote establishment of e-business payment system and make perfect online payment means.

\section{Establishing and perfecting Chinese legal regulations for e-business}

Our existing trade laws were constituted based on the traditional paper trade, so a lot of regulations don't fit into e-business, and might bring a great many unconquerable obstacles for the development of e-business. In order to ensure the development of e-business, and considering relative network management, information safety, financial settlement, and intellectual property rights protection, etc., we should quick the steps for modifying the existing laws, establish and perfect a whole set of policy statutes and regulations. That is to say, the legal system for e-business should not only accord with China's characteristics, but also be geared with the international standards.

\section{Strengthening construction of information infrastructure}

In terms of strengthening the information infrastructure construction, we should bring into the competition mechanism, cut down on charge from the network users, and improve the service quality and level to increase the utilization rate of network. Besides, traffic transportation and financial service play a fundamental part in the utilization of e-business, so we should positively promote the electronification of traffic transportation medium and financial medium, and form the e-business logistic and capital network. Furthermore, we should also break the industrial separated management system and increase the resource benefits.

\section{References}

Cao, Jie, and Liu, Ning. (2005). A Research on Application of E-business in International Trade. Journal of Nanjing University of Finance and Economics, Nanjing University of Finance and Economics, Nanjing, Jiangsu Province, January , pp. 48-54.

Ma, Jian. (2008). Impact and Strategy Study of E-business on International Trade. Northern Economy, Inner Mongolia Development and Reform Commission, Hohhot, Inner Mongolia, July, pp.33-34.

Zhang, Xu. (2007). Impact of E-business on International Trade. Finance and Economics, Southwestern University of Finance and Economics, Chengdu, Sichuan Province, July, pp. 112-117. 